\title{
Disability and Sociology: Anatomy is Not Destiny
}

\author{
Gustavo Martins Piccolo* \\ Federal University of São Carlos, Brazil \\ *Corresponding author: Gustavo Martins Piccolo, Federal University of São Carlos, Brazil. \\ To Cite This Article: Gustavo Martins Piccolo. Disability and Sociology: Anatomy is Not Destiny. Am J Biomed Sci \& Res. 2019 - 6(1). AJBSR. \\ MS.ID.000986. DOI: 10.34297/AJBSR.2019.06.000986.
}

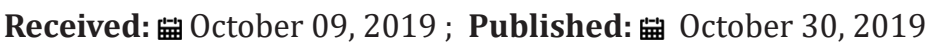

\begin{abstract}
Summary
This article deals with the need to understand and conceptualize disability beyond biological lineaments. It presents the possibility of sociological understanding of the phenomenon, the historical transformation of the concept of disability, as well as the fruitful possibilities of human development from the full and complete insertion of the disabled into society and work. It concludes by demarcating the historical task of society regarding the transformations of social and economic conditions that surround us today.
\end{abstract}

Keywords: Disability; Society; Biology

\section{Introduction}

Talking about disability through a sociological look brings with it the urgent imperative to analyze the secularization of such a phenomenon, understanding it from other than mythical and supernatural bases. The endeavor proposed by this task requires tracing the constitutive elements of sociology itself, a process of the utmost seriousness. Nisbet [1], in a seminal text, defines sociology as a modern science of core and base. Its appearance is related to the context engendered by the English Industrial Revolution (economic transformation) and the French Revolution (political transformation), and the consequent advent of political etymologies rooted in the ideas of progress, individual, contract and reason, which marked a space of split towards the social ties of the Medievo. Roughly speaking, sociology is concurrent with the future of individualistic rationalism, the genesis of industrialization, and the assumption of the state as a cardinal disciplinarian of social relations, whose analytical focus lies in the rational explanation of the world. Its emergence is linked to a series of specific events and circumstances, coinciding with the final moments of the breakdown of feudal society and the consolidation of capitalist society.

The eighteenth century emerges as an effective milestone for the creation of sociological science (although the word only appears in the nineteenth century in Comte) due to its political, economic and cultural transformations arising from the materialization of the two revolutions already mentioned and also through the establishment of social problems. unprecedented for society at the time, such as: salaried labor and alienation; the laborious discipline and the new notions of time and space implanted by machines; the issue of urbanization; the dismantling of the patriarchal family and morality previously established as dominant and, fundamentally, the emergence of two opposing classes (bourgeoisie and proletariat). On these elements the Sociology finances its leather of relations. Since then, the incessant task of building a system of thought that renounces the supernatural explanations of everyday phenomena towards scientific and rational clarification has been the same. It is therefore misleading to think that the primordial task of Sociology was revolutionary in principle, quite the contrary, its genesis is related to accommodating things in an unstable age. Singular, in this sense, presents the evolutionary model proposed by Auguste Comte and his proposal for understanding the history of human development. Comte [2] suggests that the human intellectual process can be divided into three stages: theological, metaphysical, and positivist, with the first two merging into space and time. This model suggests the passage, as history progresses, from an interpretation of reality from the religious point of view to another of naturalistic origin, later overcome by the rise of the scientific way of understanding the natural and social world. For Oliver [3], this evolutionary model proved useful in understanding the development of the change in the historical perception of deviance, which as a moral and legal problem is now analyzed through biomedical control mechanisms. Similarly, Albrecht [4], points out that a review of medical practices throughout history, even when medicine was not even established as knowledge, allows us to understand the deviation from three paradigms that reigned 
each in a given historical period, the name, the idea of deviance as sin, the deviation as a crime and subsequently the deviation as disease, the which, however, does not mean that the thought assent to a linear perspective on certain event.

History is one and diverse, and phenomena are interpreted from a myriad of concomitant positions, hence the importance of the Gramscian concept of hegemony, understanding it as a set of ideas and power structures that clothe themselves with dominant authority and cognitive guidance historical era. In the typically modern way of thinking, the body that expresses differences beyond those taken as variations of human nature itself is no longer understood from mystical evidence or providences from the sphere of the divine, into the etymological field of biological inaccuracies. This phenomenon is uniquely portrayed by Foucault [5] when he points out that with the prevalence of the medical narrative about the body, a new discourse authorized by modernity, much of what concerns the supernatural has lost its strength and meaning and what was previously seen as punishment or wrath of the gods came to be coded as pathology derived from certain clinical conditions. Since the eighteenth-century medicine has established itself as one of the fields of knowledge in close connection with state power, intuition of violent repression about the body and, above all, to deviate from certain previously established pattern.

It is about this scenario and only in its spectrum, according to Canguilhem [6] that we witness the birth of the abnormal body, an abnormality seen as a derivative in irremediable antagonism to normality, which should not be confused with the naturally most probable, even because this concept is defined in a normative and hierarchical way. The normal is a dynamic and controversial concept that also involves what is supposed to be, the basis of which is clearly axiological. For Canguilhem [7], there is no normal and pathological in themselves. The pathological is not the absence of norm, but another norm. Even so, in his view [7], theoretically it makes no sense to take our life from an alleged relationship between the normal and the pathological, because "the concept of normal is not a concept of existence susceptible in itself to be measured objectively. The pathological must be understood as a kind of the normal, since the abnormal is not that which is not normal, but that which is a different normal. Thus, the abnormality cannot be seen only as negativity, amorphous phenomenon and latent passivity, because although it can represent, on several occasions, a reduction in creative potential, never left and never cease to materialize a new life marked by original physiological constants.

It is therefore a groundbreaking experience concerning the living being, not just a diminutive fact or in subtraction contributions. It is not a variation of the health dimension, but a new dimension of life. The natural never ceased to be cultural. These relationships are not even envisioned by classical knowledge in the field of disability, not least because one of its main bastions of discrimination, to cite, would be the concept of the ideal type or average man. Without norm there is no ideal type. Without this, there are no deviants. What if there are no deviants how to justify the intrinsic social inequality experienced by various groups? In order not to have to answer this question and to confront the very structure upon which it rests, the capitalist system creates thousand mechanisms in order to demarcate a supposed objectivity of the norm. We seek the norm at all costs, which is ideologies through a rigid process of technical instrumentation that intends to make visible and quantifiable the differences and deviations previously interpreted as divinatory fruits. A natural order is established, which coincides with the dominant groups, and seeks to numerically demarcate all that is distinguished from this order.

The deaf is a normal person subtracted from the faculty of hearing. Oppositions define it. The homosexual is, above all, a nonheterosexual. The woman not a man. The black one not white. The blind a non-seer. The wheelchair a non-walker. It is the absence that defines those who depart from the supposed norm. In this sense, every reference to the possible order is intrinsically accompanied by the aversion of the possible reverse order. The different from the preferable is not the indifferent, but the refutable, the obnoxious, the one to avoid. More than one definer, the norm holds an implicit element of segregation. However, we must not lose sight of the fact that the norm never erases the difference, quite the contrary, it demarcates it at an early stage and then considers it of lesser value. Disability is not denied by society, but explicitly recognized for later being bombarded by deleterious meanings of the most diverse species. The combination of these elements makes Canguilhem [6] consider the idea of normality as a cutoff point in the process of social inclusion or exclusion expressed by capitalist societies. What escapes it can only be included margins, an inclusion by exclusion.

Of course all societies throughout their history have defined patterns of inclusion and exclusion, but in none of them have we seen limits as rigid and narrow as those imposed by the capitalist system and its maxim of the useful and productive body, as we have pointed out earlier, demarcated no longer by the divine and mystic, but by the medical and biological. Unique in this sense is Davis's [8] reasoning, for whom after the emergence of the concept of norm, the state that people longed for was an unattainable ideal. To resemble the creator spiritually was the goal, but everyone knew that such objective would never be reached. No one was extirpated for it. With the advent of modernity and the norm the power relations and raison d'être of the ideal man change completely. Being ideal now meant having a body fit for machinery and industrial paraphernalia. Failure to reach this somatic and psychic stage was the reason for the highest social refusal, a sign of discredit and disability, of dependence. The norm, under the auspices of capitalism, gives rise to a quasi-gardening culture where one cuts and prunes all the elements that are not considered major.

The strengthening of this essentially abstract, almost metaphysical concept acts as a conservative force that explicitly 
aims at preserving social structures. The material fills with the ideological. Those who distinguish themselves from the norm are debased by the norm and end up experiencing psychological and socioeconomic conditions of extreme, often irreversible disadvantage, whose improvement would fall hypothetically only to the arms of medicine. Deviation from the norm is only corrected by medical practice, which turns the deviated into patients, those who resist submissive, who depersonalize themselves. It is on the path of these relationships that disability will be worked on and conceptualized in modern societies: a problem of order and medical derivatives, an individual deficit that can only be remedied through clinical and therapeutic designs. So deeply rooted in our minds and everyday practices, this conceptualization seems to constitute an unquestionable form of explanation of disability, a naturalistic vector that amalgamates a simple cause-and-effect relationship materialized in the idea that this condition carries an intrinsic disadvantage to its biological condition.

However, there is nothing natural about such a relationship, because as we point out, it is a product built under the auspices of the consolidation of the capitalist regime and its modus operandi. Medicine imposes itself on deficiency only and exclusively on modern tropes. Thus, as naturalistic as it may seem, the medical explanation is nonetheless a heuristic device for characterizing disability, as is, albeit from other perspectives, the social model, which we will portray later. Whether or not referring to this supposed heuristic device, the values, knowledge and explanation fingered on this phenomenon unequivocally follow the path of these perspectives, even when we are not even aware of the existence of these explanatory models, as Oliver [9] points out. In most times, not being aware of these models has meant adhering to a posture in strict coherence with the individualistic lineage of interpretation of disability, a phenomenon justified due to the massive diffusion and recognition achieved by medical knowledge in the most diverse social spheres. But after all, what does the individual model of disability consist of? What is your base of support?

\section{The Individual/Medical Disability Model}

Said model is anchored in a set of assumptions and knowledge originating in the Health Sciences, with the hallmark the treatment of disability as a deviation to the normality anatomic bio-physiological; to trace this arch in the opposition between healthy and unhealthy, therefore, no longer referring to moralistic contributions as we witnessed in premodern times. Since the emergence of the individual model, according to Stiker [10] "we no longer speak in terms of good and evil, divine and evil, but sanitary/ morbid or hygienic/unhealthy. There is what is healthy and what is dangerous. No one else supports the speech of good and evil, surpassed by medical scrutiny". Historically, the individual model emerges as an explanatory device erected within the processes of constitution of modern society and his way of thinking man in society, whose formative core is in the replacement of the magical and mythical forms of explanation of disability so common until the age.

Average for scientific reasonableness and supposedly objective explanation of the phenomenon. The logic of apprehension is radically reversed, so if previously disability has been interpreted as a kind of divine punishment due to the impurities of the parents or even as a demonic work, it nowadays acquires a status of failure, limitation and incapacity to be explained by the lens of industry, biology, statistics and medicine, guardians of the state and transmitter of the official knowledge that surrounds it. The disabled individual appears. It is necessary to understand the above statement as a result of the subject's detachment process in relation to the great collective that surrounded him until the Middle Ages. The large families that spanned several generations practically ceased to exist and gave way to the nuclear family, centered on the wife, father, and children only. The motto God bless you all is replaced by each one for you and God for all. The destiny of each one now no longer depends on a network of fraternal relations, but only and exclusively on the forces themselves. With the rise of capitalism, the individual, isolated and private appears definitively in history, forging the individual we know today.

The further capitalism advanced and the higher its development became the more individualized man became. This high state of development brought new problems of order and social control in its composition. Among this set of problems, the body appears as the carrier of new variables, being divided not only between rich or poor, fed or malnourished, submissive or indolent, strong or weak, as we observed in previous historical stages. Is now also defined between usable, conducive to profitable investment, those with prospects of higher or lower degree of survival and of course those who are useful to receive the new training and discipline required to machine-managed production. In the words of Oliver [9], Prior to this time, the contribution that the individual provided to the production of social wealth was not computed by head and detached from the group. The family, the community, the clan, finally, the collective produced and all were evaluated by the production. Everyone's success, injury as well as possible sanctions as well. Already in capitalism this situation is reversed. Now it is the individual who produces.

Only he is responsible for his production and the sanctions are applied on his body. Not of the family, of the community, but of the body of the individual, whose failures are interpreted as synonymous with his failure. This new reality, together with the idea that the bodies of people with disabilities would not accommodate to the postulates of capitalist society and wage labor eventually exclude them from this space, thus being controlled by what we might call the economics of exclusion. This process of exclusion became even more pronounced when medical science was definitively established as the ideological arm of the state and the interests of capital. Such an intervention model is rooted in an 
overemphasis on clinical diagnosis and visualization of disability as a tragic and inhibitory nature of humanity to become. Disability becomes, under the medical nickname, a problem of the individual, who must take responsibility for their situation. They are now blamed for the continuing failures of their insertion into the social body.

On this blaming and medicalization of disability rests the individual model that has decisively marked the interpretation of this phenomenon in modern societies. Thus, not necessarily the dominant character assumed by medical knowledge meant an effective democratic transformation regarding the possibilities of enjoyment and cultural appropriation by people with disabilities. That there has been a transformation in the understanding of this category in society is indisputable, however, we believe that the biologist approach should not be the last word in terms of disability. There is no linearity between the predominance of medical knowledge over the religious as correlating with a more democratic attitude towards the phenomenon of disability. If we look closely at history, we realize that many of the self-fulfilling prophecies about the incapacity for social inclusion of people with disabilities have been delineated exactly from the medical perspective. This perspective has defined in terms of synonymy deficiency and disability. These are identical terms in this field, accentuated by efficiency and capacity.

A perverse conceptual binarism that keeps the opposite pole of social enjoyment is maintained through the definition of an ideal type, which reserves to those who deviate from the dominant patterns of behavior, functionality and aesthetic contributions all kinds of possible storms that make their full insertion difficult society. Within this perspective, the linear transfer of the social nonadjustment of the disabled person to his physiology and deviant body is notorious, that is, a complex social issue is addressed as the sole and exclusive responsibility of the individual. When we start from this normative assumption, we imply the idea that people with disabilities will only integrate into society when they transform their deteriorated organic condition and regain a supposed state of normativity. Therefore, any possibility of intervention that is not focused by medical knowledge is removed. And it is to this set of prerogatives presented that Oliver [11,12] calls the individual model of disability.

The alluded body of knowledge enjoyed unwavering prestige until the throes of the twentieth century, when in its last quartile it begins to be criticized viscerally, at least as regards the naturalness of discrimination against the disabled. Not surprisingly, therefore, that even in areas such as sociology, epistemologically interested in symbolic production and materials of social conflicts, echoed and still echo almost unison voices of a speech composed of theoretically unrelated lines the historical constitution of disability, reiterating the position taken by Oliver [9] that over decades and decades, disability has been treated as a pre- sociological theme by much of the human and social sciences, which considered it a social problem only when medicine had previously diagnosed and scanned it. It is not part of a foundation that has been eaten with impunity, so the sociological basis in interpreting disability, when it was rarely considered, ultimately referred to the novelty interests of medical definitions, thus, at most, sociology colonized by the parameters of the biological. It was necessary to conceive and not just describe the phenomenon, it was urgent to outline a social model of disability.

\section{For a Social Model of Disability}

The cornerstone of the theoretical construction of the Disability Studies/social model of disability pulses from the conceptual rupture of any alleged causal link between disability and impairment-injury already materialized in the far manifest granted by UPIAS, being singular the words of Finkelstein [13], that "disability is imposed upon our disabilities by the way we are unnecessarily isolated and excluded from full participation in society. People with disabilities are therefore an oppressed group in society". This view is shelter in Oliver [12] and Barnes [14], which highlights the failure in-lesion theoretical scheme of the social model can be, broadly speaking, regarded as a body characteristic such that skin color or sex. Exemplary is the practical and concrete definition of the distinction between injury and disability made by Morris (1991, p.25), for whom, in short terms we can define disability and disability quite simply. The inability to walk represents an injury, while the inability to enter a building because entry can only be done by a flight of steps is a disability. An inability to speak is an injury, but an inability to communicate because proper technical aids are not available is a disability. An inability to move a body is an injury, but an inability to get out of bed because adequate physical help is not available is a disability. Disability is a product of social exclusion.

In this theoretical architecture it becomes perfectly understandable to have an injury and not to experience the disability, whose achievement depends on the degree of flexibility of society to adapt to the most diverse differences, materiality clearly far from becoming practical. This creates a new concept of disability that has the peculiarity of being both native and analytical. Analytical because it allows the analysis of a certain set of phenomena, in this case disability, and only makes sense in the body of a given theory, anchored in the need to bring sociology to the explanation of disability, whose basis is given in the lineament of writings of Marx. Native for being a category that arises from the very experience of the group in question. It is the experience of disability that comes to be seen as a bridge to its definition, so that concept also acquires a practical, effective, historical, objective and specific sense for a particular human group. Under this intersection lies the main strength of the concept of disability expressed by the social model in that it manages to blend seemingly contradictory structures. The native and most common to people with disabilities is also the most complex in the academic field, a dynamic difficult to observe in other social movements. 
The individual model of interpretation of disability has never achieved such a feat, quite the contrary, because it establishes a striking gap between the experience of disability and the writings about it, coming from a body of professionals, which in most cases do not have a relationship of disability familiarity with the subject. The concept created by the social model starts from the idea that one social fact, disability, could only be explained by another social fact (notion of clear Durkheimian varnish), the oppressive capitalist society, with the aim of creating a sociological concept for disability that could replace the previous, bio-based one. This distinctive form of analytical inquiry arises academically in a historical context in which black scholars sought to create a new concept for race and to explain discrimination as a social product and not derived from any biological composition. The similarities are evident and contributory to both movements. In this sense, the definition of Guimarães [15] is visceral, when he is asked what race is. He says It depends. It really depends on whether we are speaking scientifically or whether we are speaking of a real-world category.

This word "race" has at least two analytical meanings: one claimed by genetic biology and the other by sociology. Biology and physical anthropology created the idea of human races, that is, the idea that the human species could be divided into subspecies, such as the animal world, and that such a division would be associated with differential development. moral values, psychic and intellectual gifts among human beings. To be honest, this was science for a while and only then became pseudoscience. We also know that what we call racism would not exist without this idea that divides humans into races, into subspecies, each with its own qualities. It was she who hierarchized human societies and populations and founded a certain doctrinal racism. This doctrine survived the creation of the social sciences, the cultural sciences, and meanings, supporting insane political postures of disastrous effects such as genocide and holocaust. Only after the tragedy of World War II did we see an effort by all scientists - biologists, sociologists, anthropologists - to bury the idea of race, disallowing its use as a scientific category. What is race in biological terms? A mistake, a profoundly intentional historical error.

The construction based on physiognomic traits, phenotype or genotype, is something that has no scientific support. What about race in sociological terms? Now, just because knowing that race does not exist biologically, and blacks continue to occupy the worst social positions is a concept that is useful in sociology. One is almost the antithesis of the other, because while biology seeks to justify discrimination and prejudice, in the field of sociological concept, ways of directly addressing these forms of oppression have been sought. Thus, race is not only a political category necessary to organize resistance to racism in Brazil, but it is also an indispensable analytical category: the only one that reveals that the discriminations and inequalities that the Brazilian notion of 'color' entails are effectively racial and not just 'classy'. Just as the sociological concept of race is diametrically distinct from that defined by biology, the deficiency conceptualized by the social model is radically different from that defined by the individual model. Both one and the other area since then seen in terms of social oppression by an insensitive society difference. Sociologically speaking race and disability are not watertight concepts like those derived from the biological matrix, they are concepts that are just like class, in a continuous process of formation.

It is never permanent, because it strengthens and changes with the modification of society. In fact, for sociologists who study racial themes and for the authors of the social model, the consideration of race and disability as biological categories is a historical mistake if we assume that the nominal, effective and effective existence of these terms only materializes in the world. Social. However, intersectionality with race studies is not the most explicit evidence of linking disability studies with other minority groups. Starting from the idea of distinguishing between biological and social, the analytical separation promoted by Disability Studies between injury and disability is embodied as a clear parallel to gender studies. The concept of gender emerges as a response given by critical sociology, in the 70's of the last centuries, to the analyzes based on the natural difference between male and female, justified the inequality in the most diverse spheres in which men and women were considered in society. Therefore, gender should be understood as a social construction whose direction sought to study the inequalities presented by men and women in their process of insertion in the scenario of history.

Rather than explaining inequalities through a biological and naturalistic variant, the gender category, while not disregarding the biological differences that exist between men and women, considers that on the basis of these, others are built on the set of values established as dominant; which radically interfere with the social insertion and educational possibilities offered to men and women in the daily sphere, in short, transform gender differences into social and cultural inequalities. For Scott [16], gender is an analytical category useful to the entire history of humanity and not only the history of women, because its scope allows the study of various inequalities, hierarchies, oppressions and discrimination in the set of social relations; Though it may cast reflections on the history of women in particular, as well as that of men, however, this particular needs to be collated by the general, which in this case is given by the continuing relationship between men and women. Appropriating gender studies, the authors of the social model established the cardinal differential of their gnoseological concept, to cite, the differentiation between injury and disability.

Like gender, by emphasizing the fundamentally social character of gender-based divisions and highlighting that embedded in the biological differences between women and men are socially and culturally constructed, disability studies emphasize that based on injury, other Differences are constructed and clutter the possibilities of insertion into the collective, eventually leading to 
the phenomenon of exclusion. This phenomenon is called disability, which is not unilaterally related to the lesion, but rather to the organization shaped by the capitalist modus operandi. Just as sex would not explain the oppression suffered by women in society, whose concreteness should be sought in its patriarchal structure, the injured body would not determine the socio-political-cultural phenomenon of the subordination experienced by the disabled in capitalism, which could only be explained by the material basis of production of this system in conjunction with personal and institutional prejudice. To explain the condition of printed oppression on the disabled due to loss of skill caused by injury or any biological disorganization was to confuse injury and disability, such as gender and gender. Disability is a material and symbolic product of society, while injury can be understood as an expression of human biology.

Drawing a parallel with gender studies we can highlight that disability can be compared to what represents gender in these studies, a social construction, in contrast, injury would be the equivalent of sex, fruit of nature. Just as the gender role of each gender is the result of a long process of socialization, the transformation of the meaning of the lesion into disability is also a strictly social one. There is nothing natural about it, indeed nothing that is essentially human is. These situations are made clear by the social model, which lies beyond the understanding of disability as a tragic problem of isolated occurrence of some less fortunate individuals for whom only medical treatment is left to view it as a situation of collective institutional discrimination for which the only appropriate response is political action radically reverses the vectors that shaped its understanding in society. Commenting on this process, Diniz [17] points out that the removal of the disability from the field of nature and its transfer to society was a revolutionary theoretical shift, such as that caused by feminism: it was no longer possible to justify the oppression of the people disabled by a dictatorship of nature, but by a social injustice in the welfare division, a statement with disconcerting political implications.

Since then the disability category has come to be a social device of exclusion, which penalizes certain people for not meeting the expectations of the average population in terms of appearance, behavior or economic performance. If it is society that disables people with disabilities, the only way to change reality is through intense struggles to transform the current state of forces and take control of their own lives. The new universe created by the social model opposes to the colonizing discourse expressed by normative, medical, clinical and rehabilitative knowledge a critical, sociological, political, inclusive and contextualized praxis. Under the auspices of a new ontology established between disability and society, the social model decolonizes the study of disability in medical areas, leading to profound consequences in the human formation of the disabled. The radical critique of the composition of the old man with disabilities, which is driven by naturalistic prisms, creates, when consciously internalized, a new way of thinking. And when we think different, we are no longer the same.

Of course, the emergence of a new man will only really materialize with the dawn of a new society, however, and this is of fundamental importance only when people with disabilities are able to point out the path to which dialectics objectively their development is that they may awaken to the awareness of the process itself, and this implies a suspension of all that has been said and done about being deficient in society. Only then can disability arise as a category derived from history and its consequent dismantling as an assumption derived from the praxis itself that unclearly alters social structure. This is the unprecedented desire of the social model to build a body of knowledge that can effectively be called emancipatory research on disability. Therefore, the logic of the social model is about revolution rather than reform, or using a word from Finkelstein [13], a strategy of emancipation rather than compensation.

The ultimate goal of the social model, according to Barnes [18] is nothing less than the creation of a world in which, regardless of disability, age, ethnicity, gender, sexual orientation, social class, job status, all can coexist as equal members in the community, without oppression and discrimination, and confident that the needs of each individual can be fully accommodated, moreover, the opinions expressed by these subjects must be recognized, respected and valued regardless of their position in society, even as in such a society division would no longer dictate the course of social relations and the very notion of Inequality would be seen in a series of existential crises, tending to disappear. This will be a truly democratic society, characterized by genuine and meaningful equal opportunities. It will continue to produce and increase its wealth yet direct its vector to the collective rather than the private. This equity will generate greater possibilities and, therefore, will broaden the focus of freedom over the human, as it enables effective growth through the appropriation of the characteristic differences of each subject and culture.

The creation of this new world is not called by any anticipated terminology. It is up to men to define their destinies and the name they will give them. The pressing need is to overcome capitalism and build a reality on other foundations. Of course, the creation of a new world will be an arduous and difficult process subject to falls, collapses and new falls, but rising is always necessary. One must look forward, forward. Many will call it utopia. But, as Oscar Wilde [19] has rightly pointed out in his "The Soul of Man under Socialism," "a map of the world that does not visualize any form of utopia is not worth seeing. We must think that our reality can and should be different. Humanity is always in the process of landing and anchoring in new lands. Land that is not given and needs to be cultivated, also sown with dreams". These situations show us the need to stand as a socialist. And what is socialism today? Being 
socialist in the 21st century means first of all being radical, one who takes and attacks problems in the bud. Being a socialist today is linked to a dialectical communion between universalism and particularism that also places the solution of global problems in the personal sphere.

It is to feel pain for another's pain and to rejoice in their happiness. It is feeling supportive and helpless when murdering a human being anywhere in the world. Cry the tears of other peoples. To suffer and to clash with the hunger that still plagues humanity when the conditions for its suppression are fully met. And what does socialism consist of? E m Lowy [20], we realize that there is nothing mysterious or obscure this question. To be a socialist is to reiterate that nothing should be abandoned to the blind laws of the market, even because its invisible hand has historically shown the face of the interests by which it erects its relations. The paths must be traced after a long, broad and pluralistic democratic debate. For this reason, socialism demands a true revolution that suppresses the capitalist system and opposes the power exercised by the ruling classes. It means the overcoming of a model of civilization based on productivism and consumerism, a predatory relationship with nature and a prisoner subjectivity of the mercantile system. It also means the end of racial discrimination-against the black, the mestizo, the indigenous- from the oppression of women, we would add the disabled, social inequality, environmental destruction, imperialist wars.

It means living in a place where everyone can work and where job offers are the rule rather than the exception. And this is achieved by voting, dialogue and not weapons, popular mobilization and the building of collective interests sustained by those who really need the state, the poor, democratic and necessary attainment given the conservative wave that plagues the globe as a whole we are talking about developing countries like Brazil or the great empires like the USA. Utopia? It depends. If it is nowhere, surely not. Objectified place, one that is desired in the near or distant future. This is it. Therefore, it is crucial to strip we of the well-known idea that the realization of a revolutionary ideal cannot be postponed beyond the life of the one who prescribes it. We cannot be so selfish and want everything to be resolved in our time. The time of a human life is dramatically scarce, this is the inescapable absolute of the human condition. No one transcends death, but not only at present does man live. Believing that the world will be different and established on different bases after our death cannot be seen as a religious creed or a kind of belief in the afterlife. Social history and trust in humanity lead us to rely on this path, so sooner or later we continue to believe in the emergence of a new society that breaks with all the lineage of the previous one and can indeed call itself democratic.

Even because, as Oliver [21] asserts, only an effectively democratic society will hold a libertarian concept of disability, since in the production of their own life men contract determined, necessary and independent relations of their will, relations that correspond to a certain stage of the development of material productive forces. In capitalism such relations will never realize the emancipatory yearning in its fullness and maximum possibility. Therefore, people with disabilities can no longer free themselves from the class that exploits and oppresses them while at the same time freeing society from exploitation. Exploitation societies which find in bourgeois relations their last stage and ultimate antagonistic form of the social process of production, which create the conditions for the very overcoming of this antagonism and allow the closure of the prehistory of humanity. This other humanity can finally be branded as a free society that enables the maximum development of all its beings. In Marcuse's view, these are the qualitatively different characteristics of a free society. They presuppose, as you may have already seen, a total overvaluation of values, a new anthropology.

They presuppose a kind of human being that rejects the performative principles that govern established societies; a kind of human being who has freed himself from the aggressiveness and brutality inherent in the organization of the established society and the puritanical, hypocritical morality; a kind of human being who is biologically unable to fight wars and create suffering; a kind of human being who is well aware of joy and pleasure and who works collectively and individually for a natural and social environment in which such an existence becomes possible. A kind of human being in solidarity and in communion with the other. How to do this? Although historical materialism seems to be the best way to explain and propose projections about reality, there are still no recipes or easy solutions. As points Adorno [22] and this question surpasses me. Faced with the question 'what to do' I can only really answer, in most cases, 'I don't know'. I can only try to analyze intransigently what it is. And that, which is the case with disability, lies in the fact that it is produced historically and socially. By way of these elements, social model theorists radically reject the idea as present in the medical knowledge of people with disabilities as dependent and needy in the most diverse welfare cuts, and also refute the dissipated assumption that they need to adapt to society. This is because they place the responsibility for exclusion on the shoulders of the so-called normalization society, rigidly developed over structures designed to create a docile workforce and reward only those considered highly productive. This way of interpreting the phenomenon allows us to analyze disability from the perspective of social creationism, since it allows the visualization of it as a reality produced by certain economic, cultural and political structures of society, so the idea of people with disabilities as an oppressed and discriminated group regains meaning. From a Marxist perspective on the political economy, people with disabilities are viewed as being excluded from the labor market not because of their personal or functional limitations, as in the individual model, nor by the discriminatory attitudes and practices of other. example of interactionism, but fundamentally due to the social organization that work assumes under the auspices of capital. 
The production of disability, therefore, is nothing less than a set of activities specifically oriented towards the production of a good, the disability category, supported by a series of political actions that create the necessary conditions for these productive activities to take place and be supported by a discourse that legitimizes them. According to Oliver [12], his criticism is directed at this company and the structure that underpins it, so he reiterates that it makes no sense in terms of political struggle to improve the condition of all people adjective the deficiency of their own lesion. That said, in the words of Oliver [12], As for the specificity of the terminology that I will use in my speech as a tool to fight against any form of oppression I will use the term disabled person in a generic way, because I refuse to divide the group in terms of medical conditions, functional limitation or severity disability. In my view, people with disabilities are defined on the basis of three criteria, namely: a) have a disability; b) are oppressed because of their disability; and c) identify themselves as disabled, regardless of whether intellectual, physical or sensory. The use of the generic term does not mean, under any circumstances, that it does not recognize the differences in experience between the various groups, but I assume that everyone suffers some form of oppression because of their condition.

Accordingly, the idea of using disability as a generic term is not to erase differences, but to create a common ground for the sum of forces of these differences with regard to the critique of capitalism and the pursuit of a rigorous theory of disability embedded. In Marxist canons. It is evident that deficiencies differ among themselves within different categories and also within the same divisions as to the needs that each person may present. The need for housing of a physically disabled child working-class daughter living in overcrowded conditions in a housing estate is not the same as that of a physically disabled child, but a daughter of the elites. On the one hand housing is almost an absence. On the other, a presence that can boast to certain levels of luxury. People's needs and differences are distinct because they are fundamentally historical and not biological, even though this sphere interferes with their attainment. People do not exist simply as disabled. Are disabled and men or women, workers or unemployed, black or white, native or migrant, etc. Therefore, the difference exists and is undeniable.

This has never been a problem and never has such a relationship been forgotten by social model theorists. The key point, therefore, is not its existence, but who defines difference as difference? How should we understand the difference? How does difference designate the other? What norms are assumed from which a group is marked as different? How are the boundaries of difference constituted, maintained or dissipated? What is the nature of the assignments that are taken into account to define a group as different? Does the difference differ laterally or hierarchically? These are the fundamental questions, some developed, others to be developed as part of the realization of the social theory of disability.
The theme of disability from a sociological perspective subverts, including the much-declaimed Marxian aphorism that the anatomy of man is the key to the anatomy of the ape by pointing out that in bourgeois society it is the most developed historical organization, most distinguished from production, which allows to penetrate the articulation and relations of production of all forms of missing societies, on whose ruins and elements it is built, and whose traces, not yet surpassed, it dragged along, developing all that was previously only indicated, thus taking all its form significance etc.

The anatomy of man is the key to the anatomy of the monkey. What in the lower animal species indicates a higher form cannot, on the contrary, be understood only when one knows the higher form. The bourgeois economy provides the key to the economy of antiquity. In terms of economic analysis, this proposition is valid to the present day, but as far as human development is concerned, it is extremely flawed and its inadvertent and misleading use has allowed a series of comparative excrescence that most refer to evolutionary knowledge of the human being than anything else when we are referring to disability studies. As Rousseau rightly pointed out, man is born twice, first to exist and then to continue the species; first as being itself and then as being for itself, the general rule of humanization that differentiates human beings from any other species. In this sense, human beings are unique, incomparable and whose development has remarkable turning points. Being deficient in a society that is still unprepared architecturally and socially indicates remarkable developmental pathways that cannot be compared to any ideal type. Part of this necessary and possible development is hampered by the difficulties created about the disability of being in the labor market, the achievement of which represents the most democratic that would exist in building public policies for people with disabilities. The goal of any modern democracy is the same in everyone: to build a society in which work is the rule rather than exception and that this principle applies to absolutely everyone. Anatomy is not destiny.

\section{References}

1. Nisbet R (2003) “The two revolutions". In: The formation of sociological thought. Buenos Aires, Amorrutu, Argentina.

2. Comte A (1973) Positive Philosophy Course. Sao Paulo, Brazil.

3. Oliver M (1997) Changing the social relations of research production. Disability, Handicap and Society 7: 101-115.

4. Albrecht G (1976) The Sociology of physical disability and rehabilitation. University of Pittsburgh Press, USA.

5. Foucault M (2000) Words and things. São Paulo, Martins Fontes, Brazil.

6. Canguilhem G (2005) Writings about medicine. Federal University of Rio de Janeiro, Brazil.

7. Canguilhem G (2006) The normal and the pathological. Federal University of Rio de Janeiro, Brazil.

8. Davis K (1990) Simple disability. Monographic studies presented in University of London, England.

9. Oliver M (1996) Understanding disability: from theory to practice. Macmillan, UK. 
10. Stiker HJ (2006) Disabled bodies and societies. Dunod, Paris.

11. Oliver M (1986) Social policy and disability: some theoretical issues. Disability, Handicap \& Society 1: 5-17.

12. Oliver M (1990) The Politics of Disablement. Macmillan, Basingstoke.

13. Finkelstein VA (2001) Personal Journey into Disability Politics. Leeds University Centre for Disability Studies.

14. Barnes C (2007) Disability Activism and the Price of Success: A British Experience. Carfax, London.

15. Guimarães ASA (2003) How to work with "race" in sociology. Educ Researched 29(1): 93-107.

16. Scott JW (1998) The Invisibility of Experience. Project History 16, São Paulo, Brazil.
17. Diniz D (2007) What is disability? São Paulo, Brazil.

18. Barnes C (1999) Disability Studies: New or Not So New Directions. Disability \& Society 14(4): 577-580.

19. Wilde $O$ (1996) The Soul of Man under Socialism. L\&PM.

20. Lowy M (2005) Leon Trotsky: Prophet of the October Revolution. October Magazine $3^{\text {rd }}$ edition.

21. Oliver M (2008) Social policies and disability: some theoretical considerations. In: Barton L (Org). Overcoming Disability barriers: 18 years of "Disability and Society". Morata, Spain p: 19-33.

22. Adorno TW (2003) Philosophy changes the world by holding on to theory. New Moon 60: 131-139. 